\title{
The Use of Factor Analyses in Validating Filipino Needs Scale in Tertiary Education
}

\author{
Dr. Ryan Dale B. Elnar \\ Department of Psychology \\ University of Mindanao, Philippines
}

\begin{abstract}
Needs is a psychological construct considered to be one of the facets of personality since need researches has shown its strong potency in predicting behaviors. The present study tested the factor structures of a need measure among Filipino university students purposely for academic and psychological interventions. Employing qualitative analysis to determine need items in the initial study, findings show that the developed factor structures composed of clustered need items is robust to test students' needs as it attains an excellent overall internal consistency $(\alpha=.94)$. As homogeneity of all measured factors are highly correlated (range: .751-.902), other need constructs (BPNS and EPPS Scales) also reveals strong concurrent validity to the need measure's factor structures. Series of factor analyses such as the use of exploratory and confirmatory factor analyses exhibits similar structural findings which yielded to a 1-factor-6-higher-order need measure. Moreover, the scale's fit indices indicated a very good fit model: $\chi^{2}$-df $\quad(540.876 ; 307)$, GFI $(0.800)$ AGFI $(0.889)$ TLI (0.874) RMSEA (0.072). Research findings were discussed in terms of the scale's efficacy to diagnose specific academic issues and broadly in indentifying learning gaps of college students in tertiary schools.
\end{abstract}

\section{INTRODUCTION}

The current research have drawn strength from the Self-Determination Theory (SDT) propagated by Deci and Ryan (1991) and how it is incorporated in the school programs, given much strong attention on the notion that students who are given their choice, interest, locus of causality (has purpose for them) and feedback achieved better outcomes in terms of psychological needs: autonomy, competence, and relatedness (Jeno, Grytnes, \& Vandvik, 2017). In accord to SDT and e-learning, the research of Han (2017) among 121 South Korean makerspaces' (students who are engaged in creative activities in informal physical spaces inside school or community settings) environmental supports significantly correlated their self-motivation in learning and thus improves intention to stay and eventually in finishing their course. Student motivation shown have shown that the prevalence of increasing career indecisions and high dropout rates among college entrants are due to lack of non-academic programs that improves learning motivation in some college courses (Elnar, 2014; Pintrich, \& Zusho, 2007; Roksa \& Whitley, 2017).

SDT's utility in schools is also studied in the light of student academic motivation and it was found out that those students who have an intrinsic drive to learn is the most effective means in information literacy (Kurbanoglu, 2010; Maybee \& Flierl, 2016; Ross, Perkins, \& Bodey, 2016), digital technology knowledge (Reynolds, Arnone, \& Marshall, 2009), and physical activity (González-Cutre et al., 2016) . These findings pose a beneficial challenge to tertiary schools to determine those students who are motivated and those who are not. The cited studies, in addition, profusely suggest that the drive of the school to focus on how students perform in class can be thoroughly reinforced by identifying their needs and ultimately used as 
basis for an institutional need support systems and programs as Deci and Ryan (2016) puts it "we suggest that educational outcomes are often too narrowly focused on performance in specific areas, whereas we see higher-quality learning and development occurring most optimally in contexts of need support."

\section{Development of Need Measure's Factor Structure}

Collecting data about students' needs is a critical component of instruction and academic or behavioral interventions. For instance, the study of Burns, Vance, Szadokierski and Stockwell (2006) described Glasser's (2001) five basic needs: physiological (survival) and psychological needs (power, belonging, freedom, and fun). The central thesis of Glasser's theory is that individuals make choices according to basic needs that are innate but shows to be different in degrees from person to person.

The study of LaFond (2000) tested the psychometric utility of a need scale aligned to Glasser's choice theory. The scale attained high content validity. However, confirmatory factor analysis did show low item correlations. This means that further item revision is required for this need measure or scale. In 1995, the 20-item Basic Needs Survey (BNS) was validated by Harvey and Retter asking the students to rank four varied activities from most desirable to least desirable represented by each item of psychological need. Despite test-retest resulted to high reliability (.66 to .79), a minimal difference between the subscale scores for each of the needs was found. However, the variation on gender between children in grades three through five and those in grades six through nine would mean the instrument is in consistent with relevant psychological theories which support the validity of data from the scale. The BNS study describes the overall need structure, however it does not provide the specific measure on how well the school is meeting the students' needs.

\section{Validating Needs Scale: Implications to Student Outcomes}

The study of Guiffrida, Gouveia, Wall and Seward (2008) reported the development and validation of a college need questionnaire focused on relatedness called as the Need for Relatedness at College Questionnaire (NRC-Q) based on the perspectives of Ryan and Deci (1991). This instrument was developed and tested to identify the needs of college students of color (CSC) based on the assumption that relationships developed at school could be a salient motivator that could influence college success. Results of the study supported the content validity, internal consistency, temporal stability, and construct validity of the scale items. Confirmatory factor analysis likewise supported the factor structures of the scale.

In the same research, further analysis revealed that the scale items have shown negative significant correlation with the items measuring college students' intention to drop out in a way that it is consistent with the self-determination theory. However, a strong positive relationship was found between NRC-Q and those theoretically similar constructs of Educational Participation Scale (EPS), particularly the scales for social contact and relatedness with peers, and family togetherness and relatedness at home. Moreover, testing the divergent validity of some scales revealed negative relationships of NRC-Q scales and the asocial/withdrawal and internally focused scales of the Millon Index of Personality Styles (MIPS) of Millon (2004) which points to the fact that the developed scales are not only reliable but valid as well.

\section{Research Design}

\section{RESEARCH METHODS}

This current research employed a mixed-method research design but largely based on quantitative design. Identifying the factors that would determine the structure of the 
instrument was dependent on the available theories, studies and existing tools measuring needs. Qualitative investigation was also conducted to verify the presence of the identified need factors. The attainment of construct validity for each dimension was carried out through exploratory and confirmatory factor analyses. The reliability of the instrument was established using internal consistency analysis and test-retest. This research design is particularly based on the mixed methods of research of Creswell (2009).

\section{Participants}

A total of 650 university students participated in this study. Table 1 show that 200 of them were involved in the internal consistency study, and a combined total of 450 participants were involved in the two factorial analyses studies. The participants' demographics by age ranges are 15 to 28 years old. Out of the nine courses offered in involved university, almost 65\% of them were enrolled in Education, Criminology, and Business Administration courses. The remaining 35\% are the students who were enrolled in Arts, Sciences, and Technology-related courses. The total number of female participants was 406 which constitute $62 \%$ of the entire study population while there were only 244 or $38 \%$ male participants who were involved across the three phases of the study. Using a convenient sampling method, all involved participants reported the ability to read, write, and understand texts written in English language.

Table 1. Participants across the Three Phases of the Study

\begin{tabular}{lc}
\hline Phases of the Study & $n$ \\
\hline Internal Consistency Analysis (Item Reliability) & 200 \\
Exploratory Factor Analysis (EFA) & 300 \\
Confirmatory Factor Analysis (CFA) & 150 \\
\hline Total & $\mathbf{6 5 0}$ \\
\hline
\end{tabular}

\section{Instruments and Scale Development Procedures}

The initial 204 items culled from literature analysis, focused-group discussions, and survey or opinionnaire to a large number of college sample were validated by experts composed of psychologists, academicians, and school administrators in various tertiary schools which eventually reduced the items into 114 . The remaining 114 items was subjected to test-retest reliability study among 84 college students. The 17 items that were deleted did not pass the required value of .05 for item stability. Thus, only 97 items were utilized for the construct validity (EFA, CFA).

Other measures that were utilized in the second phase of the study are the Edward's Personal Preference Schedule (EPPS) and Basic Psychological Needs Scale (BPNS). EPPS is composed of fifteen subscales contain psychological needs derived from Henry Murray's (1938) theory of needs. Discriminant and convergent validity was likewise established while the EPPS internal consistency range of .65 to .91 and test-retest reliability of the test items were found reasonable at three-week interval. The instrument was used for concurrent validity because the bases of its dimensions were culled from Murray's (1951) need press perspective who cited that prepotency of needs may ensue if the need is not satisfied in which this validation study is line with this perspective.

On the other hand, BPNS is one of the current innovations in developing needs construct based on the self-determination theory of Deci and Ryan (2000). This 21-item need scale has considerable validity and reliability to measure the three basic psychological needs of the college students such as autonomy, competence and relatedness. Reliability and validity of the 
items are well established and considered to be a highly researched instrument. BPNS and EPPS were used by the researcher by comparing the scores of the measures' dimensions (factors) with the need scores for concurrent validity.

Aside from ethical statutes of research were considered in the conduct of this research, test development process proposed by Cohen, Swerdlik, and Sturman (2013) was adapted. After test conceptualization, test construction through factor identification, literature analysis, and item analyses were initially conducted. Refinement of the draft items was further validated by experts before its reliability and validity testing to separate samples. Later, more samples were used for exploratory and confirmatory analyses to validate the created one-dimensional model.

\section{Data Analysis}

The development of test items was carried out through item analysis. Item analysis is a set of methods used to evaluate test items. A logical validity of items was determined using the formula of Lawshe (1975) for content validation ratio (CVR):

$$
\mathrm{CVR}=\frac{\mathrm{ne}-(\mathrm{N}-2)}{\mathrm{N} / 2}
$$

where $\mathrm{N}$ is total number of panelists, and ne is the number of panel indicating the item as "essential".

To test if the items interrelate and represent similar content, an internal consistency coefficient was examined using Cronbach Alpha $(\alpha)$ to the overall test scales. The researcher used the formula developed by Cronbach (1951) which was elaborated by Kaiser and Michael in 1975 (Cohen, Swerdlik \& Sturman, 2013). The formula for coefficient alpha is:

$$
r_{\alpha}=\quad 1-\left(\frac{k}{k-1}\right) 1-\left(\frac{\Sigma \sigma^{2}}{\sigma^{2}}\right)
$$

where $r_{\alpha}$ is the coefficient alpha, $k$ is the number of items, $\Sigma$ is the sum of variances of each item, and $\sigma^{2}$ is the variance of the total test scores.

To test the stability of the items, test-retest reliability was conducted by comparing the items of the two test administrations using Pearson $r$. The formula for Pearson $r$ is:

$$
r=\frac{\Sigma_{\mathrm{xy}}}{\sqrt{\left(\Sigma \mathrm{x}^{2}\right)\left(\Sigma \mathrm{y}^{2}\right)}}
$$

where $\Sigma_{\mathrm{xy}}$ is the sum of the product of the paired $\mathrm{x}$ and $\mathrm{y}$ scores, $\Sigma \mathrm{x}^{2}$ is the sum of the squared $\mathrm{x}$ scores, and $\Sigma \mathrm{y}^{2}$ is the sum of the squared of y scores.

Also, an exploratory factor analysis (EFA) was performed. This type of analysis determined the number of factors scale and which items were loaded on each factor which implies a mathematical attempt to simplify sets of data (Kline, 2010). Constructs were developed by looking at the items that correlated highly with each factor and deducing the meaning of the factor. This can be carried out by entering the items, setting an Oblimin rotation that provided adequate measure or interpretability of the factors according to a set eigenvalue of equal to but not less than 1. In addition, Cattell's scree plot aided the researcher in terms of interpretability and theoretical coherence of the different models to determine if the factor can be retained. 
The plot showing severely skewed items were deleted. The sampling adequacy of sample data was tested by Kaiser-Meyelin-Olkin (KMO) which should not be below the recommended cutoff of .60 (Kaiser \& Michael, 1975).

To test if the hypothetical model fits the actual data, a confirmatory factor analysis (CFA) was likewise performed. Factor loadings had helped the rsearcher in finding out the extent to which the factor determines the test scores. Thus, several indices were examined, including the chisquare $\left(\chi^{2}\right)$ goodness-of-fit statistic, root mean square error of approximation (RMSEA), Tucker-lewis Index (TLI), Adjusted Goodness of Fit Index (AGFI), and Comparative Fit Index (CFI). The goodness-of-fit statistics evaluate the model and determine how well competing models fit the data. To attain quality of items, certain threshold per fitness indices were adapted from various experts: For the $\chi^{2}$ goodness-of-fit statistic, a $\chi^{2}$ value that is less than twice the model's degrees of freedom indicated an acceptable overall model fit (Hu \& Bentler, 1995). In addition, the RMSEA is an absolute fit index that assesses how well a priori model reproduces the sample data ( $\mathrm{Hu} \&$ Bentler, 1999). RMSEA values < 0.06 are considered to indicate good fit between the hypothesized model and the observed data (Hu \& Bentler, 1999). Finally, the CFI is an incremental fit index where fit is determined by comparing a target model with a more restricted, nested base model (Hu \& Bentler, 1999). Values of 0.95 or greater indicate acceptable model fit (Hu \& Bentler, 1999).

\section{Reliability and Construct Validity}

\section{RESULTS AND DISCUSSION}

The overall internal consistency of the items demonstrates an alpha value of .931 which appeared an excellent value as compared to the acceptable value of .7. It was also gleaned from this method that none among the try-out items (114) were candidates for deletion. Items that passed the internal consistency were later used in the factor analyses procedures. Internal consistency by dimension (factor) was also checked. The overall Cronbach Alpha of .94 is robust enough to considered as stable factors which exceeds the acceptable alpha value of $\geq .70$ (Furr \& Bacharach, 2014). It henceforth provides the researcher a positive outcome on the reliability of the instrument, as measured by item stability and consistency if taken as a dimension. The consistency of each dimension coheres with the ideas of Cohen et al. (2013) that the reliability of a test should be stable over time and should be internally consistent. Similarly, the findings of Burns et al. (2006) on the psychometric measure of five basic needs concur to the present internal consistency findings.

A series of factor analyses were used by the researcher to examine the dimensionality of the identified dimensions or subscales of the need measure called College Needs Assessment Scale (CNAS). CNAS contain initially grouped items subsumed in the following need subscales: family attachment (FA), career exploration (CE), self-management (SM), spiritual enrichment (SE), affective integration (AI), and personal autonomy (PA). Two procedures were performed that attained the construct validity of these six subscales: (1) inter- correlation analysis among subscales and the total score of the need measure and (2) concurrent validity of CNAS subscales with two similar constructs (EPPS and BPNS).

The homogeneity among subscales and the total score of CNAS was carried out through intercorrelation analysis which resulted to a significant correlation at .01 confidence level as shown in Table 2. None among the examined subscales have shown low correlations suggesting that the dimensions are highly unified to a single variable or construct. This goes to show that the different subscales of CNAS measure the same construct and can be a good diagnostic tool to measure the needs of the college students, thus in turn can give better perspectives to educators, counselors and psychologists in understanding the current state or relevant 
concerns of the students. According to Tinto $(1987,2005)$, proper diagnosis on students' needs and understanding or providing better services are important steps in students' completion of their courses.

Table 2 shows the homogeneity of the instrument by examining the inter-correlations of the subscales and the total score of CNAS. At .01 significant level, the table shows high correlation of all tested dimensions, thus none of the item statements were subjected for re-evaluation.

Table 2. Inter-correlations of Subscales and the CNAS' Total Score

\begin{tabular}{ccccccc}
\hline Subscale & FA & CE & SM & SE & AI & PA \\
\hline Family Attachment & - & & & & & \\
Career Exploration & $.499^{* *}$ & - & & & & \\
Self-Management & $.548^{* *}$ & $.673^{* *}$ & - & & & \\
Spiritual Enrichment & $.649^{* *}$ & $.538^{* *}$ & $.714^{* *}$ & - & & \\
Affective Integration & $.690^{* *}$ & $.637^{* *}$ & $.697^{* *}$ & $.774^{* *}$ & - & \\
Personal Autonomy & $.695^{* *}$ & $.548^{* *}$ & $.639^{* *}$ & $.706^{* *}$ & $.841^{* *}$ & - \\
UMNAS Total & $.858^{* *}$ & $.751^{* *}$ & $.810^{* *}$ & $.851^{* *}$ & $.902^{* *}$ & $.873^{* *}$ \\
${ }^{* *}$ Correlation is significant at the 0.01 level (2-tailed) & & & &
\end{tabular}

The second approach that affirmed the construct validity of CNAS was comparing two similar measures to the examined variables (subscales) of the instrument. The measures used for this procedure were the Basic Psychological Needs Scale (BPNS) and Edward's Personal Preference Schedule (EPPS). Tables 3 and 4 both reveal concurrent validity of CNAS dimensions with the dimensions of BPNS and EPPS.

Table 3. Concurrent Validity of CNAS' Subscales with BPNS (n=37, 12 Males, 25 Females)

\begin{tabular}{cccccccc}
\hline Subscale & FA & CE & SM & SE & AI & PA & $\begin{array}{c}\text { CNAS } \\
\text { Total }\end{array}$ \\
\hline Autonomy & $.356^{*}$ & $.405^{*}$ & $.442^{* *}$ & .276 & .205 & -.006 & $.376^{*}$ \\
Competence & .199 & $.363^{*}$ & $.473^{* *}$ & $.583^{* *}$ & $.410^{*}$ & .198 & $.518^{* *}$ \\
Relatedness & .226 & .218 & $.344^{*}$ & $.564^{* *}$ & .281 & $.360^{*}$ & $.467^{* *}$ \\
BNS Total Subscale & $.356^{*}$ & $.450^{* *}$ & $.580^{* *}$ & $.671^{* *}$ & $.418^{*}$ & .268 & $.633^{* *}$ \\
\hline
\end{tabular}

* Correlation is significant at the 0.05 level (2-tailed)

**Correlation is significant at the 0.01 level (2-tailed)

Table 3 shows the concurrent validity of CNAS' subscale with BPNS. At .01 significant level, the $.633^{* *} \mathrm{r}$ value disclosed a high level of association between the total scores of CNAS and BPNS. The table further figured out a significant relationship of the CNAS' subscales with the BPNS total scores except the Personal Autonomy (PA) subscale (.268) which did not pass the .05 cut off limit. However, in the specific correlations between the examined subscales, SelfManagement (SM) correlates with all subscales of BPNS, thus attaining an overall correlation value of .580. Family Attachment (FA) did not show correlations with Competence (.199) and Relatedness (.226) except Autonomy (.356*) which passed the .05 significant level. On the other hand, Career Exploration (CE) correlates with the subscales Autonomy $\left(.405^{*}\right)$ and Competence $\left(.363^{*}\right)$ but did not show any relationship with the subscale Relatedness (.218). 
Table 4 shows another concurrent validity comparing CNAS and EPPS. Concurrent validity of CNAS' subscales with EPPS has the following results: Family Attachment (FA) positively correlates with Order $\left(.428^{*}\right)$ and a negative correlation of Aggression $\left(\mathrm{p}<.01 ;-.544^{* *}\right)$, while Career Exploration (CE) negatively correlates with Autonomy $\left(\mathrm{p}<.05 ;-.502^{*}\right)$ and Endurance $\left(\mathrm{p}<.05 ;-.446^{*}\right)$. On the other hand, the table shows that CE also positively correlate with Achievement $\left(\mathrm{p}<.05 ; .441^{*}\right)$ and Affiliation $\left(.542^{* *}\right)$. In addition, two of the EPPS subscales positively correlated with Self-Management (SM). SM positively correlated with Achievement $\left(\mathrm{p}<.05 ; .441^{*}\right)$ and Affiliation $\left(\mathrm{p}<.05 ; .570^{*}\right)$, and has negative correlation with Autonomy $\left(\mathrm{p}<.05 ;-.441^{*}\right)$.

Moreover, the Spiritual Enrichment (SE) subscale did not correlate (either positive or negative) in any of the EPPS subscales, while Affective Integration (AI) positively correlate with Aggression $\left(\mathrm{p}<.05 ; .515^{*}\right)$. Finally, Personal Autonomy (PA) subscale shows a negative correlation with Affiliation $\left(\mathrm{p}<.05 ;-.495^{*}\right)$.

Table 4. Concurrent Validity of CNAS' Subscales with EPPS ( $n=22,10$ Males, 12 Females)

\begin{tabular}{ccccccc}
\hline Subscales & FA & CE & SM & SE & AI & PA \\
\hline Achievement & .062 & $.487^{*}$ & $.441^{*}$ & -.049 & .274 & -.268 \\
Deference & .293 & -.185 & .262 & .230 & .184 & .182 \\
Order & $.428^{*}$ & .014 & .030 & -.010 & .266 & .168 \\
Exhibition & -.361 & .088 & .152 & .113 & .351 & -.063 \\
Autonomy & -.302 & $-.502^{*}$ & $-.441^{*}$ & .152 & .081 & .353 \\
Affiliation & .181 & $.542^{* *}$ & $.570^{* *}$ & .021 & -.284 & $-.495^{*}$ \\
Intraception & .388 & -.108 & -.039 & .113 & .000 & .389 \\
Succorance & .091 & .026 & .172 & .275 & -.122 & .034 \\
Dominance & .143 & -.239 & -.050 & -.096 & -.138 & .371 \\
Abasement & .447 & .670 & .991 & .319 & .554 & .220 \\
Nurturance & -.117 & .083 & .019 & .215 & -.058 & -.193 \\
Change & -.039 & .168 & -.247 & -.080 & -.118 & -.275 \\
Endurance & .144 & $-.446^{*}$ & -.204 & -.249 & .042 & .377 \\
Heterosexuality & -.156 & .163 & .064 & -.141 & .377 & .081 \\
Aggression & $-.544^{* *}$ & -.117 & -.155 & -.075 & $.515^{*}$ & .064 \\
\hline
\end{tabular}

* Correlation is significant at the 0.05 level (2-tailed)

**Correlation is significant at the 0.01 level (2-tailed)

\section{Exploratory Factor Analysis}

Tables 5 present the results of the exploratory factor analysis conducted by the researcher. The data was screened using Kaiser-Meyer-Olkin $(\mathrm{KMO}=0.892)$ and Bartlett's test of sphericity to measure the sampling adequacy of the EFA sample $(n=300)$. Based on the basic requirements proposed by Tabachnick and Fidell (2013), the most commonly-used is oblique rotation method (e.g. direct oblimin) while examining the factor correlation matrix for values over \pm 0.32 , and one orthogonal rotation method (e.g. the varimax rotation). An oblimin rotation was chosen by the researcher as it was posited by Kline (2010) that oblimin rotation provides simple structure of the item loadings and that each factor has a few high loadings with the rest of the loadings being zero or close to zero (i.e., less than \pm 0.10 after Gorsuch, 1983). Result shows that the sample entered for data processing was adequate, in which it surpassed the minimum criteria of .05 (Kaiser \& Michael, 1975). 
Table 5. Factorability of the EFA Data

\begin{tabular}{ccccc}
\hline Sampling Method & $\begin{array}{c}\text { Approx. Chi- } \\
\text { Square }\end{array}$ & Df & KMO & Sig. \\
\hline $\begin{array}{c}\text { Kaiser-Meyer-Olkin Measure of } \\
\text { Sampling Adequacy }\end{array}$ & & & .892 & \\
$\begin{array}{c}\text { Bartlett's Test of Sphericity } \\
\text { B. }\end{array}$ & 5016.665 & 1326 & & .000 \\
\hline
\end{tabular}

After data for exploratory factor analysis were screened for response outliers (Hunter \& Schimdt, 1990), two tests confirmed the adequateness of the EFA data of $(n=300)$ : KaiserMeyer-Olkin $(\mathrm{KMO}=0.878)$ and Bartlett's test of sphericity. The examined data turned out to be adequate surpassing the minimum criteria of .05 (Kaiser, 1974). This means that the data was enough to perform factor analysis. This further implies that the correlation matrix was not an identity matrix (Cochran, 1970).

Through objective judgment, the scree plot's Eigenvalues was also examined that determined the number of factors (dimensions) of the CNAS (Furr \& Bacharach, 2014). The plot revealed that the instrument is multi-dimensional (Figure 1). Reflecting on the set criterion of Furr and Bacharach (2014), a multi-dimensional instrument having correlated factors is considered a higher-order factors which contains several attributes but each of the dimension is homogenous measuring a specific atttibute and yet correlated to the higher-order factor measuring only one construct.

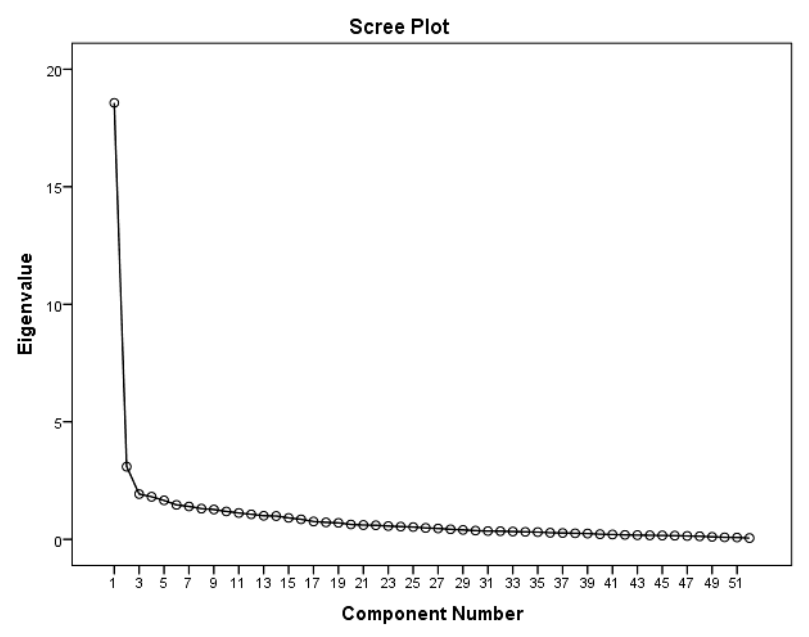

Figure 1. Scree Plot of EFA Data

After series of factor rotation, there were 13 components extracted, which explain a cumulative 74.107 percent of the total variations of the data. However, due to some item isolation issues in which other items loaded with other components, the researcher were able to come up with 28 items loading into a six-factor model, with the remaining items manually eliminated. Rozeboom (1992 as cited in Fabrigar et al. 1999) posits that components must have robust factor indices greater than 0.60 , must not load as a weaker index to other components, and that components must be comprised of at least three items.

Table 6 shows the factor loadings of the 28 items clustered in the six factors or dimensions of the CNAS anchoring on the threshold of Furr (2011) citing that any item having the factor loadings of .30 or .40 indicate reasonable value, while a factor loading value of .70 or higher is considered very strong. 
Table 6. CNAS Factor Loadings

\begin{tabular}{|c|c|c|c|c|c|c|c|}
\hline \multirow{2}{*}{$\begin{array}{l}\text { Item } \\
\text { Code }\end{array}$} & \multirow{2}{*}{ Need Statement } & \multicolumn{6}{|c|}{ Factor } \\
\hline & & F1 & F2 & F3 & F4 & F5 & F6 \\
\hline FA_86 & experience my family's love and care. & .799 & & & & & \\
\hline FA_46 & have the support of my family in what is important to me. & .785 & & & & & \\
\hline FA_41 & have a good dinner with my family. & .707 & & & & & \\
\hline FA_56 & make my family proud for having good grades. & .701 & & & & & \\
\hline FA_83 & be able to get along well with my family members. & .694 & & & & & \\
\hline FA_50 & able to resolve conflict in my family. & .664 & & & & & \\
\hline CE_110 & $\begin{array}{l}\text { explore which careers could be best fit to my interests and } \\
\text { abilities. }\end{array}$ & & .843 & & & & \\
\hline CE_112 & improve on my ability to concentrate when studying. & & .759 & & & & \\
\hline CE_103 & be clear about the kind of job I would be doing in the future. & & .710 & & & & \\
\hline CE_78 & have an on-the-job experience for the work that I want. & & .650 & & & & \\
\hline CE_94 & $\begin{array}{l}\text { have trainings on how to apply what I learned in the } \\
\text { classroom. }\end{array}$ & & .621 & & & & \\
\hline CE_16 & do an experiment to gain more knowledge of my course. & & .506 & & & & \\
\hline SE_3 & increase my knowledge of my faith. & & & & - & & \\
\hline SE_8 & live according to my faith. & & & & $\begin{array}{c}- \\
.756\end{array}$ & & \\
\hline SE_106 & grow in worship and prayer. & $\begin{array}{c}- \\
.509\end{array}$ & & & - & & \\
\hline SE_47 & serve God through others. &.- & & & -6 & & \\
\hline SM_12 & learn the skill how I could handle stress* & & & .795 & & & \\
\hline SM_82 & learn ways to overcome physical fatigue/tiredness. & & & .694 & & & \\
\hline SM_81 & manage conditions/situations that put me under stress. & & & .652 & & & \\
\hline SM_71 & be aware of my personal qualities or attributes. & & & .651 & & & \\
\hline AI_79 & know how to improve on my weakness. & & & & & .769 & \\
\hline AI_98 & have someone who would listen to me. & & & & $\begin{array}{c}- \\
.510\end{array}$ & 608 & \\
\hline AI_77 & go to places where I could relax or unwind. & & & & .510 & .602 & \\
\hline AI_84 & have a place where there is not much noise. & & & & & .500 & \\
\hline PA_52 & have the chance of choosing the right course/major for me. & & & & & & -.764 \\
\hline PA_29 & have a clear understanding about my own values. & & & & & & -.556 \\
\hline PA_67 & have the trust of my parents. & & & & & & .607 \\
\hline PA_34 & talk to a person whom I can freely express myself. & & & & & & .554 \\
\hline
\end{tabular}

The first factor (F1) has accumulated six final items (86, 46, 41, 56, 83, and 50). These combined items will measure the need for family attachment of the college students. Literature analysis suggests that these items tend to express feelings of attachment towards parents and members of the family. It likewise exhibits the person's need for family relationship despite the fact that they are at school. Therefore, family's influence is superficial and could not be taken away from the students under study (Hannum \& Dvorak, 2004; Garneau et al., 2013). Thus, the researcher fittingly named the need scale as Family Attachment (FA).

As shown in Table 6, the second factor (F2) reveals six final items $(110,112,103,78$, 94, and 16). The clustered need items concentrate on the students' need for career awareness and orientation in which sprawling researches suggest the need to career indecision, career direction, and career motivation in the lives of college students (Simmering \& Wilcox, 1995; Rodriguez, 2012; Yousefi et al., 2011) in which suited to be called as Career Exploration (CE). 
On the third factor (F3), four items $(12,82,81$, and 71) were identified to measure the students' strategies in handling situations and self-awareness. The researcher's analysis of these items reflects self-control and overcoming physical fatigue or regaining energy. Thus, the researcher suitably named them as Self-Management (SM).

The fourth factor (F4) showed in the table reveals another four items $(3,8,106,47)$. Spirituality is one of the salient aspects of human experience and this does not exclude the college students under study. Thus, combining these four items, the researcher named them as Spiritual Enrichment (SE). This is defined as the need to enhance students' level of transcendence through spirituality. The study of Piedmont (2001) cited the value of spirituality in relation to the five-factor model of personality among undergraduate students. In his final analysis, he found that spiritual constructs can be most efficacious in conjunction with multidimensional assessment battery that included other personality domains.

The fifth factor (F5) combines four inter-related items $(79,98,84$, and 77$)$. F5 is named as Affective Integration (AI) since these clustered items speaks about students' emotionality. The validation of study of Mitsopoulou et al. (2012) disclosed the value of emotion regulation which has examined its concurrent validity to the dimensions of coping strategies to an adult sample.

The last dimension identified by the principal component analysis (PCA) was the sixth factor (F6) and this factor was named by the researcher as Personal Autonomy (PA) because these clustered items are in line with the need perspectives of various proponents (Edwards, 1959; Deci \& Ryan, 1995) while it also shows that autonomy is a correlate of some psychopathological conditions (Deci \& Ryan, 1995).

One of the advantages of using exploratory factor analysis is item reduction. Item reduction is a process of eliminating the items with low factor loadings and decides whether an item has similar meanings with other items collided at one factor. The extraction method used in this research was principal competent analysis (PCA) which resulted to a 5 rotations factor analysis. Within each factor analysis, several items were automatically deleted so that the PCA can be rotated to identify again items with low factor loadings. The rotation method used was the Oblimin Oblique Rotation.

As espoused by Fabrigar et al. (1999), oblique rotation is preferred by many experts over orthogonal rotation (i.e. Varimax). This rotation method was used to further analyze the likelihood of an item for a specific dimension (factor). In this research, the series of factor analysis explained a cumulative 74.107 percent of the total variations of the data. However, due to some item isolation issues in which other items loaded with other components (Table 7), the researcher was able to come up with 28 items loading into a six-factor model, with the remaining items manually eliminated. 
Table 7. Item Elimination for Low Factor Loadings and Inter-Factor Convergence Using Oblique Rotation

\begin{tabular}{|c|c|c|c|c|c|}
\hline \multirow{2}{*}{ Subscale } & \multicolumn{5}{|c|}{ Items Deleted at 5-Rotated Factor Analysis } \\
\hline & 24-Factor & 19-Factor & 17-Factor & 15-Factor & 13-Factor \\
\hline SM & 13 & 49 & 26 & & $75^{* *}, 108\left(^{* *}\right)(*)$ \\
\hline SR & $14,4327,91$ & 73 & & & $32 *$ \\
\hline $\mathrm{AF}$ & 1,95 & $\begin{array}{c}39,10 \\
101\end{array}$ & 104 & 5 & $109^{* *}$ \\
\hline SE & $\begin{array}{c}57,72,111, \\
45,76\end{array}$ & 114 & 64 & 53 & 17 \\
\hline $\mathrm{PE}$ & $18,74,66,62$ & 23 & 44,19 & & $69 *$ \\
\hline SC & 51,88 & 65 & & & $70,68,35$ \\
\hline PA & 61 & 77 & & & $\begin{array}{c}58,67^{*}, 63,21^{* *} \\
33^{* *}, 59^{* *}\end{array}$ \\
\hline FS & 30 & & & & $4^{* *}, 11\left(^{* *}\right)(*), 42^{* *}$ \\
\hline FR & 92 & & & & $100^{* *}$ \\
\hline CE & & & & 25 & \\
\hline VS & & & & & $36^{* *}, 24^{* *}, 31^{* *}, 48^{*}$ \\
\hline
\end{tabular}

*Item with inter-factor convergence

**Item converged in the eliminated factor (with less than 4 items, Rozeboom, 1992 as cited in Fabrigar et al. 1999 )

Legend: SM=Spiritual-Moral; SR-Social-Interpersonal; AF=Autonomy-Freedom; SE=School Environment; PE=Psycho-emotional; SC=Scholastic Competence; PA=Physical-Aesthetic; FS=Financial Stability; FR=Family Relationship; CE=Career Exploration; VS=Validity Scale

The number of factors per round is as follows: round one is 24 factors, second round is 19 factors, third round is 17 factors, fourth round is 15 factors, and the final round is 13 factors. At the different rounds, there were items eliminated automatically for two reasons: (1) the item has low factor loading (value), and (2) robust inter-correlations (convergence) with other factors (Rozeboom, 1992 as cited in Fabrigar et al. 1999). Furthermore, items with inter-factor convergence has a single asterisk $\left(^{*}\right)$ and the items that were not included as one of the factors of the CNAS has double asterisk ${ }^{* *}$ ). A specific explanation is attributed to the factors with double asterisk because these were the items reflected or converged in the validity dimensions and with those factors having less than four items.

\section{CONCLUSION}

Based on the results and findings of the study, it is concluded that the formulated instrument has shown substantial evidence of reliability and validity capable of measuring the needs of the college students. One particular reason for this conclusion is that the test-retest reliability coefficients of the dimensions of CNAS were high and significant. It also showed that concurrent validity coefficient of CNAS was equally high and significant. In terms of construct validity, correlations of the measured dimensions depicted high and significant results. Further factor analyses shown that CNAS as one scale is a model composed of one factor with multidimensional correlated dimensions wherein structural equation modeling supported the fitness of this one-dimensional model. 


\section{References}

Burns, M. Vance, D., Szadokierski,I. \& Stockwell, C. (2006). Student Needs Survey: A Psychometrically Sound Measure of the Five Basic Needs. International Journal of Reality Therapy,25.2 : 4-8.

Creswell, J. W. (2009). Research design: Qualitative, quantitative, and mixed methods approaches (3rd ed.). Thousand Oaks, CA: Sage.

Deci, E. L., \& Ryan, R. M. (1991). A motivational approach to self: Integration in personality. In R. Dienstbier (Ed.), Perspectives on motivation. Nebraska Symposium on Motivation. Lincoln: University of Nebraska Press

Deci, E. L., \& Ryan, R. M. (2000). The 'what' and 'why' of goal pursuits: Human needs and the self-determination of behaviour. Psychological Inquiry, 11, 319-338.

Deci, E. L., \& Ryan, R. M. (2016).Optimizing students' motivation in the era of testing and pressure: A selfdetermination theory perspective.In Building Autonomous Learners (pp. 9-29).Springer Singapore.

Deci, E. L., \& Ryan, R.M. (2008). Facilitating optimal motivation and psychological well-being across life's domains, Canadian Psychology, 49, 14-23.

Deci, E. L., Vallerand, R. J., Pelletier, L. G., \& Ryan, R. M. (1991). Motivation and education: The self-determination perspective. Educational psychologist, 26(3-4), 325-346. Edwards, Allen (1959). Manual of Edwards Personal Preference Schedule. Psychological Corporation. USA: Harcourt Brace Jovanovich, Inc.

Fabrigar, L. R., Wegener, D. T., MacCallum, R. C., \& Strahan, E. J. (1999). Evaluating the use of exploratory factor analysis in psychological research. Psychological methods, 4(3), 272.

Elnar, Ryan Dale, Personality Traits and Occupational Interest: Basis for Career Guidance Program (2014).

Developing Country Studies, ISSN 2225-0565, Vol. 4, No. 13, 2014. Available at

SSRN: https://ssrn.com/abstract=2927395

Fabrigar, L. R., Wegener, D. T., MacCallum, R. C., \& Strahan, E. J. (1999).

Evaluating the use of exploratory factor analysis in psychological research. Psychological methods, 4(3), 272.

Furr, R.M. (2011). Scale Construction and Psychometrics for Social and Personality Psychology. Singapore: SAGE Publications

Furr, R.M. and Bacharach, L. (2014). Psychometrics. Singapore: SAGE Publications

Garneau, C., Olmstead, S. ,Fincham, D. \& Pasley, K. (2013). Therole of family structure and attachment in college student hookups. Sex Behavior. 42:1473-1486, Retrieved February 25, 2015, via proquest

Glaser, B. G. (2001). The grounded theory perspective: Conceptualization contrasted with description. Sociology Press.

González-Cutre, D., Sierra, A. C., Beltrán-Carrillo, V. J., Peláez-Pérez, M., \&Cervelló, E. (2016).A school-based motivational intervention to promote physical activity from a self-determination theory perspective. The Journal of Educational Research, 1-11.

Gorsuch, R. L. (1983). Factor Analysis (2nd ed.). Hillsdale, NJ: Erlbaum.

Guiffrida, D., Gouveia, A., Wall, A., \& Seward, D. (2008). Development and validation of the Need for Relatedness at College Questionnaire (NRC-Q). Journal of Diversity in Higher Education, 1(4), 251.

Hannum, J. \&Dvorak, D. (2004). Effects of family conflict, divorce, and attachment patterns on the psychological distress and social adjustment of college freshmen. Journal Of College Student Development, 45.1 : 27-42.

Harvey, V S., \& Retter, K. (1995). The development of the Basic Needs Survey. Journal of Reality Therapy, 15(1), 7680. http://search.proquest.com/docview/1412577988?accountid=31259

Hu, L. T. \& Bentler, P.M. (1999). Cutoff criteria for fit indexes in covariance structure analysis: Conventional criteria versus new alternatives. Structural Equation Modeling, 6, 1-55.

Hu, L. T., Bentler, P. M., \& Hoyle, R. H. (1995). Structural equation modeling: Concepts, issues, and applications. Evaluating model fit, 76-99.

Hunter, J. E., \& Schmidt, F.L. (1990). Methods of meta-analysis: Correcting errors and bias in research findings. Newbury Park, CA:Sage.

Jeno, L. M., Grytnes, J. A., \&Vandvik, V. (2017). The effect of a mobile-application tool on biology students' motivation and achievement in species identification: A Self-Determination Theory perspective. Computers \& Education, 107, 1-12. 
Kaiser, H. F. (1974). An index of factorial simplicity. Psychometrika, 39(1), 31-36.

Kaiser, H. F., \& Michael, W. B. (1975). Domain validity and generalizability. Educational and Psychological Measurement, 35(1), 31-35.

Kaiser, H.F. \& Michael, W.B. (1975). Domain validity and generalizability. Educational and Psychological Measurement, 35, 31-35

Kline, R.B. (2010). Principles and practice of structural equation modeling (3rd ed.). New York, NY: Guilford Press.

Kurbanoglu, S. (2010). Self-efficacy: An alternative approach to the evaluation of information literacy. In Qualitative and Quantitative Methods in Libraries: Theory and Applications: Proceedings of the International Conference on QQML2009, Chania, Crete, Greece, 26-29 May 2009 (p. 323). World Scientific.

Lafond, B. A. G. (2000). Glasser's Reality Therapy approach to relationships: Validation of a Choice Theory Basic Needs Scale (Doctoral Dissertation, St. Mary's University, 2000). Dissertation Abstracts International: section B: The Sciences \& Engineering, 60, 3615.

Lawshe, C. H. (1975). A quantitative approach to content validity. Personnel psychology, 28(4), 563-575.

Maybee, C., \&Flierl, M. (2016).Motivating learners through information literacy.

Millon, T. (2004). Millon Index of Personality Styles Revised. NCS Pearson.

Mitsopoulou, E., Kafetsios, K., Karademas, E., Papastefanakis, E., \& Simos, P. G. (2013). The Greek version of the Difficulties in Emotion Regulation Scale: Testing the factor structure, reliability and validity in an adult community sample. Journal of Psychopathology and Behavioral Assessment, 35(1), 123-131.

Murray, H. A. (1938). Explorations in personality.

Murray, H. A. (1951). Uses of the thematic apperception test. American Journal of Psychiatry, 107(8), 577-581.

Piedmont, R. (2001). Spiritual transcendence and the scientific study of spirituality. Journal of Rehabilitation, 67.1 : 4-14. Retrieved February 25, 2015, from http://search.proquest.com/docview/236289792?accountid=31259

Piedmont, R. (2001). Spiritual transcendence and the scientific study of spirituality. Journal of Rehabilitation 67.1 : 4-14. Retrieved February 11, 2015, from

Pintrich, P. R., \& Zusho, A. (2007). Student motivation and self-regulated learning in the college classroom. In The scholarship of teaching and learning in higher education: An evidence-based perspective (pp. 731-810). Springer, Dordrecht.

Reynolds, R., Arnone, M., \& Marshall, T. (2009). Perceived competence and reading enjoyment as contributors to information skills and digital technology knowledge. Proceedings of the American Society for Information Science and Technology, 46(1), 1-26.

Rodriguez, S. (2012).Social Support and Career Thoughts in College Athletes and Non-Athletes. The Professional Counselor: 12-21. Retrieved February 25, 2015, from

Roksa, J., \& Whitley, S. E. (2017). Fostering academic success of first-year students: Exploring the roles of motivation, race, and faculty. Journal of College Student Development, 58(3), 333-348.

Ross, M., Perkins, H., \&Bodey, K. (2016). Academic motivation and information literacy self-efficacy: The importance of a simple desire to know. Library \& Information Science Research, 38(1), 2-9.

Rozeboom, W. (1992). The glory of suboptimal factor rotation: Why local minima in analytic optimatization of simple structure are more blessing than curse. Multivariate Behavioral Research, 27.4: 585-599.

Simmering, M. ; Wilcox, I. (1995). Career exploration and identity formation in MBA students. Journal of Education for Business, 70.4 : 233. Retrieved January 30, 2015, from http://search.proquest.com/docview/202818841?accountid=31259

Tabachnick, B.G. and Fidell, L.S. (2013), Using Multivariate Statistics (6th ed.). Allyn and Bacon, Boston, MA.

Yousefi, Z., Abedi, M., Baghban, I. , Eatemadi, O. \&Abedi, A. (2011). Personal and situational variables, and career concerns: predicting career adaptability in young adults. The Spanish Journal of Psychology 14: 1, 263-71. Retrieved February 11, 2015, from http://search.proquest.com/docview/866294753?accountid=31259 